\title{
Nano-Engineering of Complex Systems: Smart Nanocarriers for Biomedical Applications
}

\author{
L.G. Guerrero-Ramírez ${ }^{1}$ and Issa Katime ${ }^{2}$ \\ ${ }^{1}$ Departamento de Química, Universidad de Guadalajara, \\ Centro Universitario de Ciencias Exactas e Ingenierías. Guadalajara Jalisco, \\ ${ }^{2}$ Grupo de Nuevos Materiales y Espectroscopia Supramolecular, \\ Facultad de Ciencia y Tecnología (Campus Leioa), \\ ${ }^{1}$ México \\ ${ }^{2}$ Spain
}

\section{Introduction}

The latest research in the area of polymeric materials focus on the design of increasingly complex devices that have a specific objective (Dubé et al., 2002). The knowledge of a world beyond our simple fire vision of research that, in turn, have generated a more complete knowledge about the surrounding environment and the development of new sciences that attempt to explain the behavior of micro scale.

Among the new sciences of the XXI century are to nanotechnology, which is still being developed. The transition from micro to nano scale will provide significant improvements in the understanding of matter and its applications (Katime et al., 2004). Nanotechnology is the study, design, creation, synthesis, manipulation and application of materials, devices and functional systems through control of matter at the nano scale and the exploitation of phenomena and properties of matter at the nano scale.

Nanotechnology requires a new interdisciplinary approach to both research and in fabrication processes (Katime, 1994). We consider two routes: the first is the miniaturization of microsystems and the second mimics nature by building structures from atomic levels molecular (Thomson, 1983). Because of the latter need emerges nanotechnology to biomedicine, science that is now channeled to the study of biological systems, largely based on the science of polymers to achieve this goal (Mendizábal et al., 2000).

One of the areas in the twentieth century has been supplemented to the science of polymers is biomedicine within it, biomaterials have the most diverse types of devices, and that demonstrate the advantages over other materials traditionally used (Lee et al., 1996). Because of its versatility, polymeric hydrogels are a special type of biomaterials whose use has expanded rapidly in many areas of medicine (Lee \& Wang, 1996). When designing a synthetic polymer is generally aimed at satisfying a need, in other words, it seeks to confer a characteristic end product that helps solve the problem for which it was designed.

There is a direct relationship between the properties of a hydrogel (or a polymer in general) and its structure, so that both features cannot be considered in isolation, since the method of synthesis has a decisive influence on them. Therefore, when evaluating the properties of the hydrogels is to be referred to the structural parameters that condition 
them $^{8}$. In the field of polymers, the term biocompatibility concerns two different aspects, but those are directly related: (a) The high tolerance have to show the tissues to the foreign agent, mostly when the polymer is to be implemented, and (b) chemical stability, and especially physics polymer material during the time that is in contact with the body. There is no single definition of smart polymer; however we can say that is one that to an external stimulus undergoes changes in its physical and/or chemical. The first time I coined the term "smart polymer" was in a newspaper article of the year 1998 (Nata \& Yamamoto, 1998). This paper described how a group of researchers from the University of Michigan using Electro-rheological fluids (ER) to create smart materials. These fluids have the potential to change viscosity almost instantly in response to an electrical current. The fact revealed the existence of a new type of material with the ability to modify its properties in a given time and adjust to changes in conditions. Two years later, in 1990, Hamada et al., Published an article in which phase transitions glimpsed a photo-induced gel (Mamada et al., 1990). A year later in 1991 appeared a review article on functional conducting polymers, which envisioned its potential application as intelligent materials (Kwon et al., 1991).

Currently there are several processes which can yield polymeric nanoparticles with a high yield of reaction, however, which allows the production of nanoparticles with high control of its features is the microemulsion polymerization. Microemulsion polymerization is a method with interesting perspectives and a type of polymerization alternative to existing processes to produce polymer latex of high molecular weight but with particle sizes smaller than those obtained in emulsion, which vary from 10 to $100 \mathrm{~nm}$ (Escalante et al., 1996; Candau \& Buchert, 1990).

Microemulsions are fluid phases, microstructure, isotropic, optically transparent or translucent, at thermodynamic equilibrium, containing two immiscible fluids (usually water and oil) and surfactants (Candau \& Zekhinini, 1987). Unlike emulsions are milky, opaque and thermodynamically unstable. The biggest difference between emulsion and microemulsion is given by the amount of surfactant needed to stabilize the system, which is much higher for the case of microemulsions $(\approx 10 \%$ of the total mass). This restricts the potential use of microemulsions in most applications due to the requirement of a formulation as cheap as possible, characterized by a high proportion monomer/surfactant (Katime et al., 2001).

Hoar and Schulman were the first to introduce the concept of microemulsion and to postulate the first mechanism for the formation of a microemulsión (Corkhill et al., 1987). The reason for the formation of a stable microemulsion is to be found in the analysis of the energies present in dispersion, a fact which can be expressed in terms of Gibbs free energy necessary for the formation of a microemulsion (Hoar \& Schulman, 1943).

The nano-hydrogels commonly exhibit volume changes in response to changing environmental conditions (Katime \& Mendizábal, 1997). The polymer network can change its volume in response to a change in the environment such as temperature, $\mathrm{pH}$, solvent composition, electrical stimulation, the action of electric fields, etc (Bokias et al., 1997). The combination of molecular interactions such as van der Waals forces, hydrophobic interactions, hydrogen bonds and electrostatic interactions, determine the degree of swelling of hydrogel at equilibrium. If a gel contains ionizable groups, is a $\mathrm{pH}$ sensitive gel, since the ionization is determined by the $\mathrm{pH}$ in terms of equilibrium ionization (Kurauchi et al., 1991). The variation of $\mathrm{pH}$ of the swelling induces changes in the degree of ionization of electrolytes and, therefore, a change in the degree of swelling of the hydrogel. Moreover, the 
temperature is one of the most significant parameters affecting the phase behavior of the gels. Recent studies show that it is possible to produce hydrogels with a particular transition temperature or even develop hydrogels with various transition temperatures (Kurauchi et al., 1991).

One of the most studied polymers, which respond to temperature changes in the external environment, is poly ( $\mathrm{N}$-isopropyl acrylamide) (PNIPA). This polymer undergoes a strong transition in water at $32^{\circ} \mathrm{C}$, from a hydrophilic state below this temperature to a hydrophobic state above it. Currently the development of polymeric complexes have bioactive properties, that are able to interact with cellular mechanisms has grown considerably because of the many applications that can take the coupling of biological receptors within the polymer matrices. One of the biological receptor that has attracted interest from the scientific community is folic acid receptor Saunders \& Vincent, 1999. The protein encoded by this gene is a member of the folate receptor family (FOLRF). The members of this family of genes have a high affinity for folic acid and reduction of various folic acid derivatives, in addition to mediate the delivery of 5-methyl tetrahydrofolate inside cells. This gene is composed of 7 exons, exons 1 to 4 encode the 5 'UTR and exons 4 through 7 encode the open reading frame. Due to the presence of 2 promoters, there are multiple transcription start sites and alternative splicing of exons, there are several variants of the transcript derived from this gen (Choi et al., 1988).

The importance of folate receptor is that in various diseases this gene is overexpressed on the cell surface that makes it easy to capture through the cellular process of receptormediated endocytosis RME (Tannock \& Rotin, 1989). Folic acid, in addition to high specificity towards the tumor tissue, offers potential advantages, including its small size, which carries favorable pharmacokinetics, reduced immunogenicity allowing repeated administration, high availability and safety (Vert, 1986). Devices for controlled release of drugs are an especially important application that exploits the collapse-swelling properties of the polymers in response. In this field are particularly important hydrogels containing poly (N-isopropyl acrylamide) (PNIP), which generate matrices that can exhibit thermally reversible collapse above the LCST of the homo polymer is taken as base (Stubbs et al., 2000).

The collapse in the structure of the matrix is accompanied by loss of water and any cosolute, as it may be a therapeutic agent or active ingredient. Drug expulsion and loss of water takes place at the initial stage of gel collapse, followed by a slower release of drug that diffuses from the gel visibly shrunken and physically compacted (Rivolta et al., 2005). A useful synthesis allows delivery systems be prepared to respond to a pre-designated value of $\mathrm{pH}$ and/or temperature to release some kind of drug. For drug delivery applications the response of the nanogels should be nonlinear with different levels of expectation and response, that is where the key is to develop materials that should show strong transitions to a small stimulus or change in the environment. One way to accomplish this is by defining the structures of micro and nano-scale.

\section{Nano-engineering of nanometric systems}

One of the main challenges in designing a delivery system directed or specific control variables is necessary for the device you are thinking about getting this necessary features for use depending on which system to be used. The case of the current treatments for cancer therapy devices required to recognize a biological marker on the surface of tumor cells, so 
that this device can act as a mechanism Tipi "Trojan horse", which tumor cell invaginates the vehicle as if it were a necessary nutrient for cellular functions. Having recognized the growing problem: How can the vehicle be able to release their cargo within the cell cytoplasm? To answer this question it is necessary to consider some facts: a) new research has shown that folic acid specific ligand is over expressed in cancer cells and can be also referred to as a tumor marker. Also, as already mentioned in this work that the folate receptor is one of the 25 receptors that mediate the endocytosis process mediated by receptors (Mathur \& Scranton, 1996) (previously described), b) the $\mathrm{pH}$ inside the tumor cell has a decrease to a value of 4.5 (Katime et al., 2009) and c) the average body temperature is near $36^{\circ} \mathrm{C}$ (Katime et al., 2008).

Focusing on these facts we can say that the design of a nanostructure that can be used to treat diseases like cancer must submit specificity, sensitivity to $\mathrm{pH}$ and temperature.

\section{$2.1 \mathrm{pH}-$ sensitivity}

If a gel contains ionizable groups, is a $\mathrm{pH}$ sensitive gel, since the ionization is determined by the $\mathrm{pH}$ in terms of ionization equilibrium. The variation of $\mathrm{pH}$ of the swelling induces changes in the degree of ionization of electrolytes and, therefore, a change in the degree of swelling of the hydrogel. Table 1 shows the functional groups that can induce changes in the polymer network to changes in $\mathrm{pH}$.

\begin{tabular}{|c|c|c|}
\hline Stimulus & Hydrogel Type & Release Mechanism \\
\hline Ionic Strength & Acidic or basic hydrogel & Change in pH-swelling-release of drug \\
\hline Chemical species & $\begin{array}{c}\text { Hydrogel containing } \\
\text { electron-accepting groups }\end{array}$ & $\begin{array}{c}\text { Electron-donating compounds-formation of } \\
\text { charge-transfer complexes-change in } \\
\text { concentration of ions inside the gel-change } \\
\text { in swelling-release of drug }\end{array}$ \\
\hline Thermal & Thermo-responsive \\
hydrogel & $\begin{array}{c}\text { Change in temperature-change in polymer- } \\
\text { polymer and water-polymer interactions- } \\
\text { change in swelling-release of drug }\end{array}$ \\
\hline Electrical & $\begin{array}{c}\text { Hydrogel containing } \\
\text { immobilized enzymes }\end{array}$ & $\begin{array}{c}\text { Substrate present-enzymatic conversion- } \\
\text { product changes swelling of gel-release of } \\
\text { drug }\end{array}$ \\
\hline Magnetic & $\begin{array}{c}\text { Magnetic particles } \\
\text { dispersed in microspheres }\end{array}$ & $\begin{array}{c}\text { Applied magnetic field-change in pores in } \\
\text { gel-change in swelling-release of drug }\end{array}$ \\
\hline
\end{tabular}

Table 1. Effect of Different External Stimuli on the release of Bioactive Molecules from Smart Nanohydrogels (Katime 2010).

Therefore, the understanding to the sensitivity to a change in $\mathrm{pH}$ for drug transport vehicle is based on the incorporation of ionizable groups within the polymer matrix. These groups will be responsible for ensuring, through its characteristics, the change in size in the pores of the polymer network with some variation of $\mathrm{pH}$. Studies by Katime 
and colleagues (2009) show that depending on the type of ionizable structure, a polymer gel can change their swelling properties - collapse before a stimulation of $\mathrm{pH}$, specifically the gels with more basic properties studied in recent years are those who owe their acidbase properties to the presence of pyridine rings in its structure molecular (Katime et al., 2005).

Pyridine is a cationic ionizable group has a pKa value of 5.2, so this functional group appears to be a strong candidate to obtain $\mathrm{pH}$-sensitive cationic gels having a $\mathrm{pH}$ of swelling $\left(\mathrm{pH}_{\mathrm{s}}\right)$ around 5 (Figure 1).

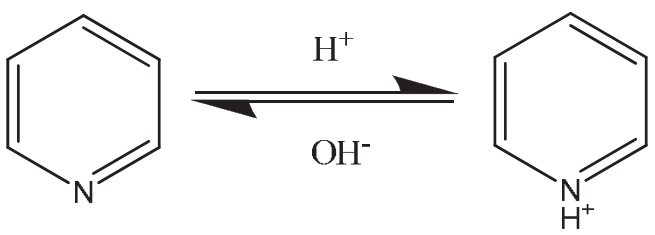

Fig. 1. Ionizing process of the pyridine ring.

One way to achieve the inclusion of pyridine functional groups is the copolymerization with vinyl monomers derived from the ionizable group, as is the case of 4-vinylpyridine (4VP) and 2-vinylpyridine (2VP). Polymerization and crosslinking leads to the obtaining of intersecting networks pyridine ring and ortho position respectively, with the carbonate skeleton of the network.
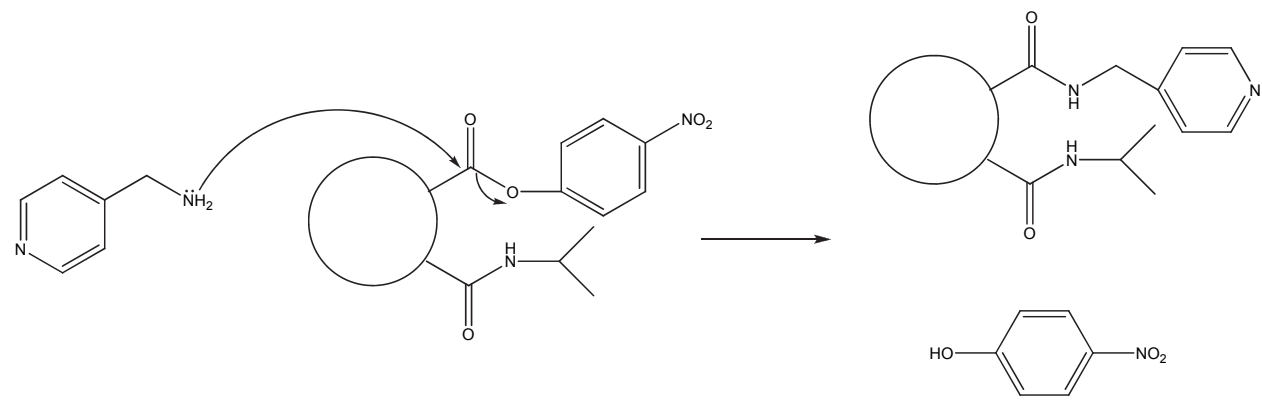

Fig. 2. Synthetic procedure proposed by Katime and coworkers to obtain microgels with ionizable pyridine groups.

Loxley and Vincent (1997) synthesized microgels by copolymerizing 2-vinylpyridine and styrene, and found its swelling at $\mathrm{pH}$ values lower than 4531, while Fernandez-Nieves et al. (2000) studied the volume phase transition of microgels obtained from the direct polymerization of 2 vinyl pyridine, finding a $\mathrm{pH}$ of swelling of 4.032 . Snowden et al. for their part, have been studied extensively in recent years cationic copolymer microgels of $\mathrm{P}$ (NIPA-co-4VP), and have found $\mathrm{pH}$-sensitive properties of swelling with $\mathrm{pH}$ change 5.5. These microgels $4 \mathrm{VP}$ derivatives, obtained by different synthesis methods have also been recently studied by Vincent et al. (2005), also found $\mathrm{pH}$-sensitive properties, although the $\mathrm{pH}$ of swelling were determined to be lower ( pH 3.5-4.0). More recently, several studies show that 4-aminomethyl pyridine (4AMP) coupled in post polymerization reactions to a crosslinked polymer network, can govern the collapse-swelling transition at a $\mathrm{pH}$ of 4.53-36 
(Figure 2), by use of molecules with "good leaving groups" allowing the incorporation of 4AMP within the polymer network (Guerrero-Ramírez, 2008).
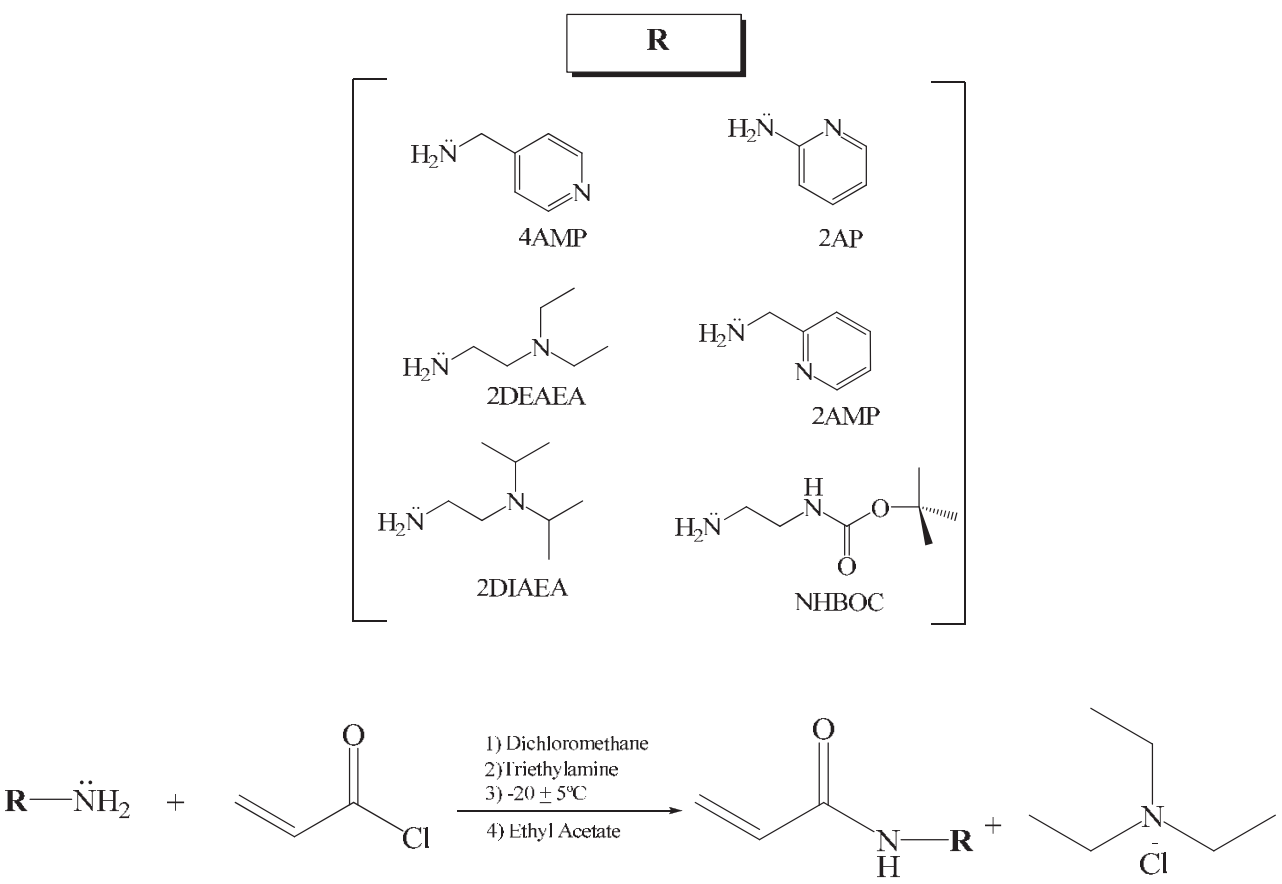

Fig. 3. Schematic procedure proposed by Katime et al. (2010) for the synthesis of aminebased monomers.

Katime et al. (2010) have proposed the synthesis of vinyl monomers from amines for potential use in modification reactions that result in the ownership of $\mathrm{pH}$ sensitivity for polymeric gels (Agüero et al., 2010). The synthesis of monomers is a simple procedure that involves a nucleophilic substitution reaction by the use of a "good leaving group (Figure 3). Such reactions have a yield above $80 \%$, which generates a good alternative to the inclusion of these compounds to drug transport vehicles.

\subsection{Temperature sensitivity}

Temperature is one of the most significant parameters affecting the phase behavior of the gels. Recent studies show that it is possible to produce hydrogels with a particular transition temperature or even develop hydrogels with various transition temperatures (GuerreroRamírez et al., 2008). One of the most studied polymers, which respond to temperature changes in the external environment, is poly( $\mathrm{N}$-isopropyl acrylamide) (PNIPA). This polymer undergoes a strong transition in water at $32^{\circ} \mathrm{C}$, from a hydrophilic state below this temperature to a hydrophobic state above it. Above the phase transition, as shown schematically in figure 4 , is based on the entropic gain associated water molecules to the side chain isopropyl substituent. 
The temperature at which this happens (called lower solution critical temperature or LCST) corresponds to the region in the phase diagram in which the enthalpic contribution of water bound to the polymer chain is less than the entropic gain of the system as whole and, therefore, depends largely on the ability to form hydrogen bonds and the chemical nature of constituent monomer units. Consequently, the LCST of a polymer can be adjusted to measure the variation in the content of hydrophilic or hydrophobic comonomers.

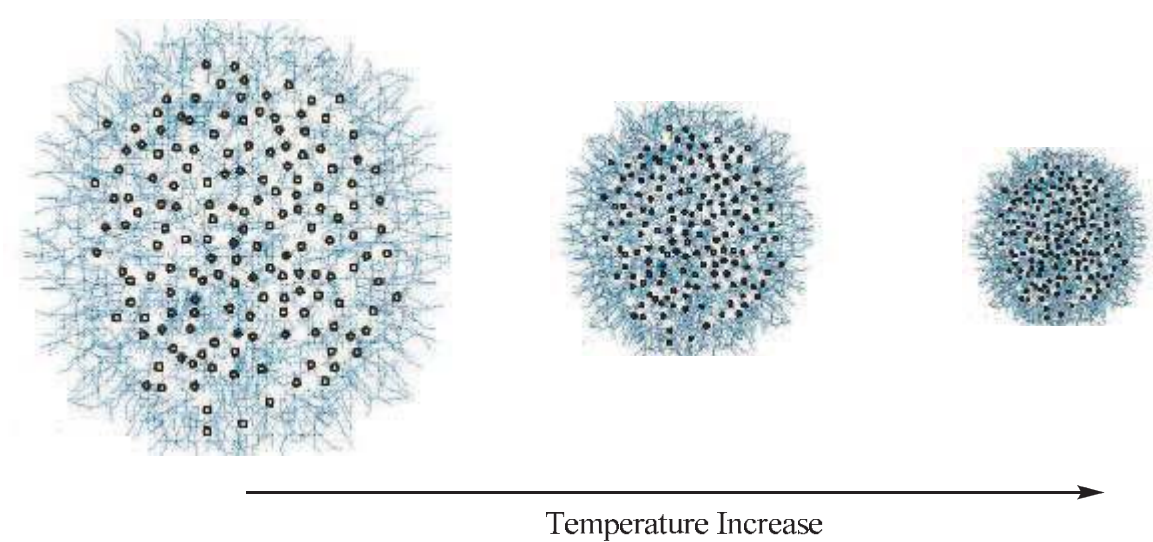

Fig. 4. Temperature behavior of typical pNIPA hydrogel.

\section{Synthetic mechanisms}

A nanogel is polymer network that is ranged between 10 to $100 \mathrm{~nm}$ of particle size. The nanogeles can present well defined structures as a spherical structure or heterogeneous structure (non-defined structure). The synthesis of nanohydrogels besides the usual elements in any polymerization such as solvent, monomer or monomers and the initiator, it requires a crosslinking agent, who will be responsible for the crosslininked structure (Hervias et al., 2008; Guerrero-Ramírez et al., 2008; Guerrero-Ramírez et al., 2008; Bruck \& Mueller, 1988; Agüero et al., 2010). For this purpose the synthetic procedure can be done using a large number of monomers that are classified divided in three different categories (Murray \& Snowden, 1995): a) Monomer with no lateral ionizing groups, b) Monomers with ionizable functional groups and, c) Zwitterionic monomers.

There are several methods for preparing crosslinked hydrogels. One of this methods that is widely use is by a chemical reaction, this method is a copolymerization and crosslinking reaction between one or more monomers and multifunctional monomers which is present in very small quantities. Initiation systems that can be used are those used in conventional polymer synthesis: thermal decomposition of an initiator, temperature, ionic initiators, gamma radiation or redox.

Also it is possible to obtain crosslinking by the polymerization of a concentrated solution which can cause self-crosslinking through the elimination of hydrogen atoms in the polymer backbone, followed by combinations of radicals. The choice of the crosslinking agent is essential to optimize the properties of the hidrogel (Orrah et al., 1988). 
There are different ways to reach a successful synthetic procedure: within which are precipitation polymerization, emulsion, microemulsion and nanoemulsion. Each is aimed at obtaining polymeric materials with different characteristics.

Among these, the microemulsion polymerization is offered more versatility because through it is possible to obtain very small particles $(10-150 \mathrm{~nm})$ by synthetic variation of different parameters within which we can find the surfactant system The oil phase, the aqueous phase, monomer ratio, the amount and type of crosslinking agent, the amount and type of initiator and the addition of compounds capable of reducing ionic micellar space.

Recently there have been reports of the synthesis of microgels using a new polymerization technique, microemulsion polymerization, which allows for smaller particle sizes (15-40 nm) than those obtained by emulsion polymerization (Zhang et al., 2002).

Microemulsion polymerization is an alternative to existing processes to produce latex containing polymer of high molar mass but with particle sizes smaller than those obtained by emulsion polymerization (Kudela, 1987; Krane \& Peppas, 1991). Microemulsions are fluid phases, microstructured, isotropic, optically transparent or translucent, at thermodynamic equilibrium, containing two immiscible fluids (usually water and oil), contrary to emulsion which are milky, opaque and thermodynamically unstable. An important difference between emulsion and microemulsion is that the amount of surfactant needed to stabilize the micromulsions (>10\% wt) is much greater than that used in the emulsions ( 1 to $2 \% \mathrm{wt}$ ). This greatly restricts the potential use of microemulsions in most applications, since it is required to use a formulation as cheap as possible (Franson \& Peppas, 1991). However, since by microemulsion polymerization it is possible to obtain monodisperse spherical microgels with diameters less than $50 \mathrm{~nm}$ (Downey et al., 1999; Tanaka et al., 1984; Osada et al., 1989) there is a promissory future for this technique.

The most important part of a microemulsion is the surfactant. Usually mixtures of surfactants are used to take advantage of each of them and their sinergy (Pelton, 2000). Surfactants are organic compounds that are amphiphilic because they have hydrophobic groups (tails) and hydrophylic groups (heads). Therefore, they are soluble in both organic solvents and water.

There are four types of surfactants: a) Anionic, b) Cationic, c) Non ionic and, d) Amphoteric. Increasing the concentration of surfactant causes the formation of microstructures, which are aggregates of colloidal dimensions that exist in equilibrium with individual surfactant molecules. The concentration at which these microstructures (micelles) are formed is the critical aggregation concentration (CAC).

The micellization phenomena is a cooperative process in which a large number of surfactant molecules associate to form a closed aggregate. When forming the micelles, the critical aggregation concentration is called critical micelle concentration (CMC). The critical micelle concentration depends on the number, length, type, branching or substitution of the hydrophobic chain and the nature of the polar group. The effects favoring micellization produce a decrease in the critical micelle concentration and viceverse.

The type of micelles that are formed depends on the properties of the surfactant and dissolution. The micellization is a cooperative process in which a large number of surfactant molecules associate to form a closed aggregate in which the nonpolar parts of the surfactant are separated from the water. The micellization process occurs through a series of conflicting effects: 1) effect that tend to favor the formation of a micelle and the hydrophobic effect, which increases with the size of the hydrocarbon chain of surfactant, and 2) effect that tend to oppose the formation of a micelle, as the repulsion between the hydrophilic groups, particularly important in ionic surfactants. 
The presence of alcohol, which is sandwiched between the surfactant molecules at the interface, or the addition of electrolytes to produce a screen effect that reduces the intermolecular electric field, reduces the repulsive forces favoring the micelización (Zhu et al., 1989).

The critical micelle concentration depends on the number, length, nature, saturation, branching or substitution of the hydrophobic chain and the nature of the polar group. The effects that favor the micellization produce a decrease in critical micelle concentration and vice versa.

When is added to the medium a salt or an ionic monomer, latex stabilization is achieved (Antonietti \& Bremser, 1990). It is known that the addition of an electrolyte to an aqueous solution produces a variation in the cloud point, i.e. the point at which the solubility changes. When this addition causes a migration of surfactant molecules into the oil phase, increasing the packing of it at the interface, it favors the formation of the microemulsion, due to an increase in the solubility by the presence of salt (salting out). If instead there is a decrease in the cloud point, there is a decrease in solubility by the presence of the salt (salting in). These phenomena are usually related to changes in the water structure around the ions which modify the interactions between water and the surfactant (Funke et al., 1998). Ions such as $\mathrm{Na}^{+}$and $\mathrm{K}^{+}$decrease the of the surfactant polar head, while ions such as SCN-and $\mathrm{I}^{-}$, favor the solvation of the surfactant making it more water soluble (Kazakov et al., 2002). In general, the introduction of an electrolyte with salting out effect causes a change in the hydrophilic-lipophilic (HLB) balance of the surfactant, shifting the optimum HLB to form a microemulsion towards higher values. Regarding the preparation method, there is a difference between these two types of dispersions, which focuses on the order of addition of components. In the emulsion case the addition order is very important, contrary to what happens in the formation of microemulsions, where it is not important.

\subsection{Inverse microemulsion polymerization}

The inverse microemulsion polymerization is based on training, pre-polymerization, microemulsion system of water in oil, which include micromicelas containing monomers to react. Within this group, with globular structure and those with bicontinuous structure.

The inverse microemulsion polymerization of monomers soluble in water is a particularly suitable method for preparing high molecular weight polymers and fast reaction rates (Nata \& Yamamoto, 1998), due to high local concentration of monomer within each particle as the growth of radical separate particles prevents termination by combination.

According to studies by Candau, throughout the reaction there is an excess of surfactant stabilizing micells (Candau \& Leong, 1985). Two populations are shown as typical colloidal aggregates: a particle with a diameter of about $50 \mathrm{~nm}$ and a micelle. It has also been observed that the number of particles increases continuously throughout the polymerization reaction due to excess surfactant, which makes the amount of micelles is at all times well above the particle, allowing for entry of radicals nucleation into micelles. According to the kinetic mechanism for the inverse microemulsion polymerization is depicted in figure 5 , the radicals are absorbed into the micelles. They react with the monomer to spread and form a polymer particle. This particle is growing due to the contribution of monomer from other micelles that act as reserve deposits. Eventually the system is reduced to two populations of polymer particles and a water swollen micelles. 


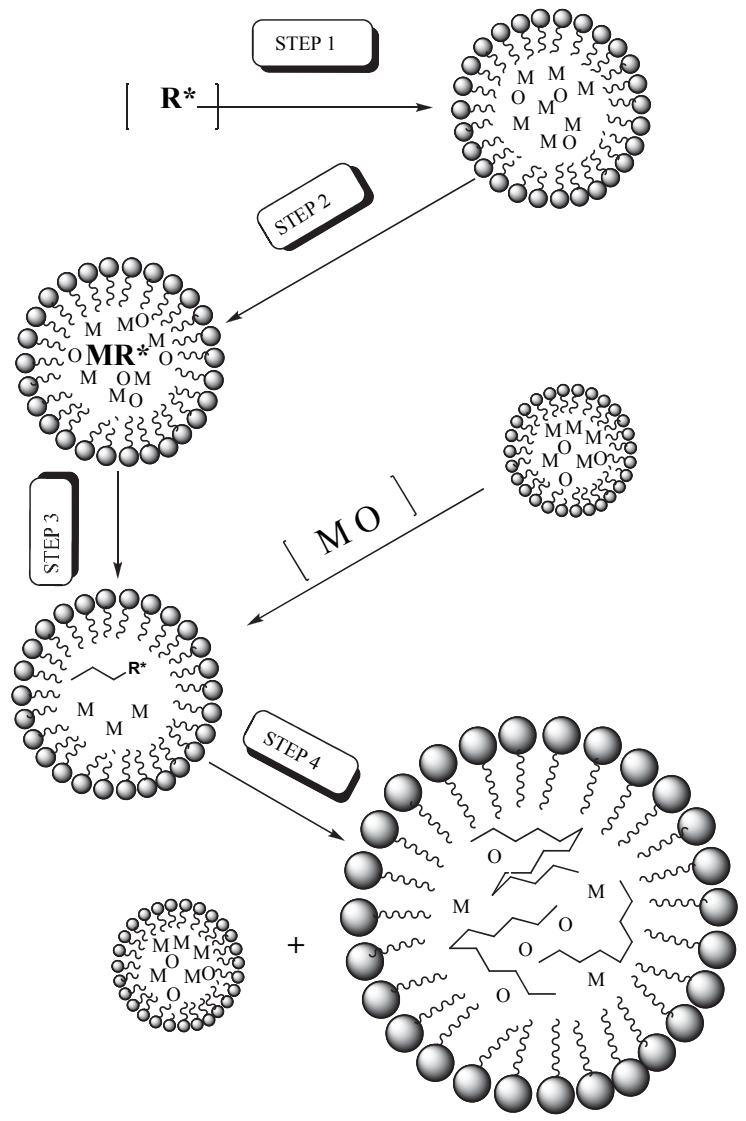

Fig. 5. Kinetic mechanism for the inverse microemulsion polymerization.

\section{Bioactive nanosystems}

Currently the development of polymeric complexes have bioactive properties, i.e. that are able to interact with cellular mechanisms has grown considerably because of the many applications that can take the coupling of biological receptors within the polymer matrices. Among these recipients are: acetylcholine receptor, cytokine receptor, insulin receptor $\mathrm{T}$ cell receptor, recipient of transforming growth factor beta, receptor phosphotyrosine phosphatase, receptor guanylyl cyclase, muscarinic receptor, M1 muscarinic receptor, muscarinic receptor M2, muscarinic receptor M3, M4 muscarinic receptor, nicotinic receptor, mineralocorticoid receptor.

But a biological receptor that has attracted interest from the scientific community is folic acid receptor (Candau \& Zekhinini, 1986). The protein encoded by this gene is a member of the folate receptor family (FOLRE). The members of this family of genes have a high affinity for folic acid and reduction of various folic acid derivatives, in addition to mediate the delivery of 5-methyl tetrahydrofolate inside cells. This gene is composed of 7 exons, exons 1 to 4 encode the 5 'UTR and exons 4 through 7 encode the open reading frame. Due to the 
presence of 2 promoters, there are multiple transcription start sites and alternative splicing of exons, there are several variants of the transcript derived from this gene.

The importance of folate receptor is that in various diseases this gene is overexpressed on the cell surface that makes it easy to capture through the cellular process of receptormediated endocytosis EMR (Bleiberg et al., 1998). Folic acid, whose chemical structure is shown in figure 6, is a natural vitamin required for transfer reactions in many metabolic processes and is now a promise in the vectorization of anticancer drugs. Several investigations in recent decades have concluded that folic acid receptors have a preferential expression in ovarian, endometrial, lung, kidney, colon, among others, but are very limited in the normal tissues (Boggs et al., 1996; Castro et al., 2005; Alléman et al., 1993; Coney et al., 1991). This specific folate-cancer cell has been used for the design of anticancer using folic acid as the ligand molecule to the director of their tumoral cells (Weitman et al., 1992; GarinChesa et al., 1993; Ross et al., 1994; Anderson et al., 1992).<smiles>Nc1nc2ncc(CNc3ccc(C(=O)NC(CCC(=O)O)C(=O)O)cc3)nc2c(=O)[nH]1</smiles>

Fig. 6. Molecular structure of folic acid.

Folic acid, in addition to high specificity towards the tumor tissue, offers potential advantages, including its small size, which carries favorable pharmacokinetics, reduced immunogenicity allowing repeated administration, high availability and safety. Moreover, folic acid is stable at very different temperatures and in a variety of solvents, and in slightly acidic or basic media, unlike antibodies that require careful handling to avoid distortion. Another point to note is that it is cheaper than the aforementioned monoclonal antibodies. All this, combined with its relatively simple chemical conjugation, makes it an interesting and promising molecule specific antitumoral therapies (Bronstein, 2004).

To determine at which $\mathrm{pH}$ these folate conjugates are subject to when passing into the intracellular environment, in studies it has been measured indirectly the $\mathrm{pH}$ of individual endosomes containing folate conjugates and it was found that although this value can vary considerably (4.7-5.3), the average pH is 5.0 (Brannon-Peppas, 1997; Tannock \& Rotin, 1989; Vert, 1986; Stubbs et al., 2000; Katime et al., 2006). This $\mathrm{pH}$ is markedly different of the physiological $\mathrm{pH}$ of the blood stream and of any healthy tissue $(\mathrm{pH}=7.4)$.

\section{Membrane cell transport: receptor-mediated endocytosis (RME)}

Endocytosis is a cellular process by which the cell introduces large molecules or particles, and does so by including them in an invagination of the cytoplasm membrane, forming a vesicle that eventually breaks off and enters the cytoplasm. When endocytosis leads to the capture of particles is called phagocytosis, and when only portions of liquid are captured is 
called pinocytosis. Pinocytosis traps substances indiscriminately, while receptor-mediated endocytosis only includes those molecules that bind to the receptor being this type of endocytosis very selective. The RME allows cells to take specific macromolecules called ligands, such as proteins that bind insulin (a hormone), transferrine (a protein that binds to iron), cholesterol carriers and low density lipoproteins.

1) The RME requires specific membrane receptors to recognize a particular ligand and link to it, 2) ligand-receptor complexes migrate along the surface of the membrane structures called coated pits. Just inside the cytoplasm, these pits are lined with a protein that can polymerize into a cage-shaped structure (membrane vesicle), and 3) The vesicles move within the cytoplasm, taking the ligand from the extracellular fluid to within the cell. The materials bound to the ligand, such as iron or cholesterol, are introduced into the cell, then the empty ligand returns to the surface.

Devices for controlled release of drugs are an especially important application that exploits the collapse-swelling properties of the polymers in response. In this field are particularly important hydrogels containing poly (N-isopropyl acrylamide) (PNIPA), which generate matrices that can exhibit thermally reversible collapse above the LCST of the homopolymer is taken as base (Mathur \& Scranton, 1996).

The collapse in the structure of the matrix is accompanied by loss of water and any cosolute, as it may be a therapeutic agent or active ingredient. Drug expulsion and loss of water takes place at the initial stage of gel collapse, followed by a slower release of drug that diffuses from the gel shrunk visibly and physically compact.

When the polymer matrix has been incorporated into a co-monomer to respond when the polymer changes state, swelling of the gel can be exploited as a release mechanism to change as a result of the expansion of the polymer. The smart nanogels have the potential to be used with a variety of drug loading and release of active ingredients as well as features and release can be adapted to a wide range of different environments (Bruck \& Mueller, 1988; Alléman et al., 1993; Bleiberg et al., 1998).

A useful synthesis allows delivery systems be prepared to respond to a pre-designated value of $\mathrm{pH}$ and/or temperature to release some kind of drug. For drug delivery applications the response of the nanogels should be nonlinear, i.e., with different levels of expectation and response, that is where the key is to develop materials that should show strong transitions to a small stimulus or change in the environment. One way to accomplish this is by defining the structures of micro and nano-scale.

\subsection{Smart nanocarriers}

Smart copolymeric nanoparticles can be synthesized using a microemulsion polymerization process using a reported method (Guerrero-Ramírez et al., 2008). The microemulsion solution was introduced in a mechanical reactor at $25 \pm 1^{\circ} \mathrm{C}$ operated at $131 \mathrm{rpm}$ and nitrogen was bubbled to maintain an inert atmosphere during the whole reaction. The monomers N (4-methyl pyridine) acrylamide (NPAM) and tert-butyl 2 acrylamidoethyl carbamate (2AAECM) are not commercial products, they were synthesized by a nucleophilic substitution reaction from the precursors, modified 4AMP and BOC, respectively. To obtain NPAM monomer, 4AMP reagent was previously prepared and reacted with acryloil chloride at $-5^{\circ} \mathrm{C}$ under vigorous stirring to produce a nucleophilic substitution by the amino functional group and releasing $\mathrm{HCl}$ to the average reaction. The 2AAECM synthesis procedure involves several steps: the first was to obtain a di-tert-butyl dicarbonate (BOC) 
modified by reaction with ethylenediamine at $-19^{\circ} \mathrm{C}$ using dichloromethane as a reaction medium and when all the BOC reactive was added the reaction was maintained for 16 hours at $25^{\circ} \mathrm{C}$. Then, dichloromethane was evaporated and the diprotected amine formed as a secondary product was separated due is insoluble in water, so water was added to precipitate system. Diprotected amine was separated by filtration and the resulting solution was saturated with $\mathrm{NaCl}$ and extracted with ethyl acetate. Then the solution was dried by adding anhydrous sodium sulphate and the final product was obtained by rotoevaporation. Finally, the resulted product of the reaction was reacted with acryloil chloride to produce an active monomer (2AAECM).

This kind of particles can be used to load, transport and deliver active drugs. These characteristics permits that smart nanocarriers be use against different diseases including cancer or tuberculosis.

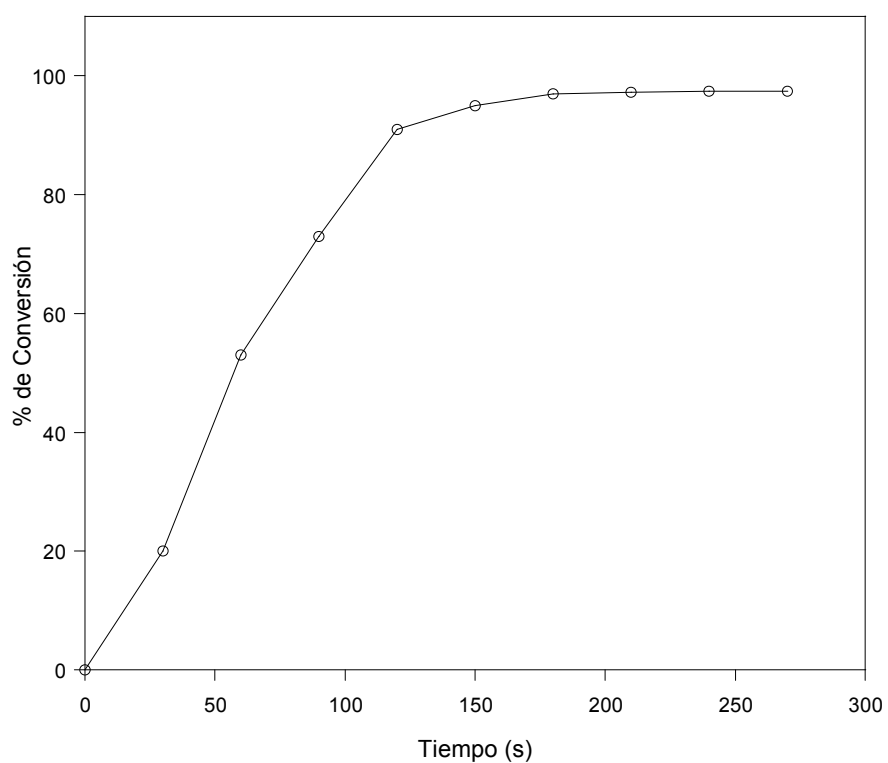

Fig. 7. Polymerization kinetics for COP23 sample obtained using a gravimetric method.

In the case of anti-cancer therapies it is also necessary the functionalization with folic acid, as it has been described, this director molecule is widely used as a biological cellular marker due to it is overexpressed in a number of human tumors, including cancer of lung, kidney and blood cells.

Dissolution of folic acid is prepared by mixing it with 1-(3-dimethylaminopropyl)-3-ethyl carbodiimide hydrochloride (EDC) and tryethylamine, at $25^{\circ} \mathrm{C}$, using magnetic stirring for one hour to produce activated folic acid. This mixture is dropped into a dispersion of nanogels in water to incorporate the guide molecule. The purification and the isolating procedure of the final product is carried out by dialysis using a phosphate buffer solution of $\mathrm{pH}=7.4$, and then distilled water. All of this procedure is performed in a dark environment to avoid degradation of the folic acid molecule. 
The total reaction time for obtaining this type of system is estimated at an average of 3 minutes. Figure 7 can be seen that reaction times higher than the 3 minutes are not a significant change in conversion rate. As low curing times, with conversions above $97 \%$, produce nanoparticles more efficiently.

An important fact is that in samples where the amount of initiator used in the synthesis is increased, decreased reaction time. For this system has not been given this trend, because as mentioned, the average reaction times for all cases are set at 3 minutes.

The particle size of several samples of smart nanogels have been synthesized, for all formulations, small particle sizes. Table 1 shows this behavior, in the same way, the remarkable effect of initiator concentration on particle size has a tendency that increasing the initiator concentration, particle size decreases. On the other hand, the particle size of the nanogels synthesized with different concentrations of crosslinking agent and different amounts of salt added, show that the particle diameter decreases nanogel depending on the content of crosslinking agent. As can be seen when the concentration of crosslinker increases, the particle diameter decreases. However, there is a concentration limit, both as crosslinking initiator, from which particle size can not decrease nanogel more.

\begin{tabular}{ccccc}
\hline Sample code & \%crosslinker & \%initiator & \% $\mathrm{KNO}_{3}$ & Dp (nm) \\
\hline COP20 & 5 & 1 & 0 & 45 \\
COP21 & 5 & 2 & 0 & 43 \\
COP22 & 5 & 3 & 0 & 40 \\
COP23 & 5 & 4 & 0 & 38 \\
COP24 & 5 & 5 & 0 & 36 \\
COP25 & 4 & 5 & 0 & 40 \\
COP26 & 3 & 5 & 0 & 42 \\
COP27 & 2 & 5 & 0 & 41 \\
COP28 & 1 & 5 & 0 & 41 \\
COP29 & 5 & 3 & 0 & 42 \\
COP30 & 5 & 3 & 0 & 40 \\
COP31 & 5 & 3 & 0 & 42 \\
COP32 & 5 & 3 & 0 & 41 \\
COP33 & 5 & 3 & 0 & 40 \\
COP34 & 5 & 3 & 2 & 35 \\
COP35 & 5 & 3 & 4 & 33 \\
COP36 & 5 & 3 & 6 & 30 \\
COP37 & 5 & 3 & 8 & 28 \\
COP38 & 5 & 3 & 10 & 28 \\
\hline
\end{tabular}

Table 1. Particle sizes of smart nanogels obtained by QELS. 
The addition of a soluble salt such as potassium nitrate $\left(\mathrm{KNO}_{3}\right)$ produced a reduction of space inside the micelles because the salt creates a series of charges in the continuous phase. They produce a reduction in size of the micelle by the action of electrostatic forces external to that micelle, thereby limiting the size of the particles. This effect can be seen in the same table, so that when the concentration of $\mathrm{KNO}_{3}$ increases, the particle size is reduced, and when the concentration of $\mathrm{KNO}_{3}$ is greater than or equal to $5 \%$ (based on the total amount of monomers). Particle size has no appreciable change and remains constant.

The micrograph of a nano-synthesized samples is presented in figure 8 , this figure shows the spherical nature of the obtained nanoparticles.

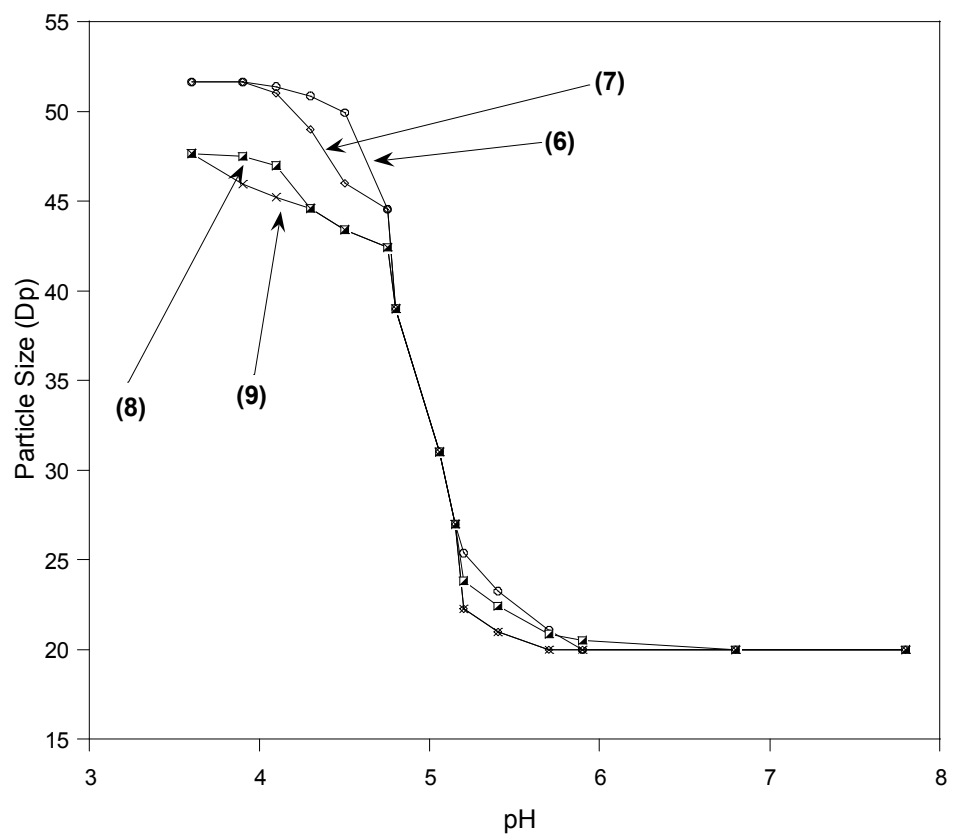

Fig. 8. Variation of particle size of the nanogels. Samples COP25(6), COP26 (7), COP 28 (8) and COP29 (9).

Moreover, when these particles are subjected to changes in $\mathrm{pH}$ values can be clearly seen as the inclusion of molecules ionizing groups within the skeleton of the system allow the nanogel have an answer "smart" to these variations. This can be seen in Figure 8, which shows that at $\mathrm{pH}$ values lower than 4.5 the nanogel is in the swollen state while values close to 5 the gel collapses.

Because these nanoparticles are designed primarily for use in cancer therapy, the choice of the active ingredient can be transported by this system must comply with the desired characteristics of an anticancer drug. For this reason we have chosen the 5 -fluorouracil (5FU). 5FU is a drug that blocks the methylation reaction of acid to convert deoxyuridylic thymidylic acid, by inhibiting an enzyme that is important for the synthesis of thymidine. 
<smiles>O=c1[nH]cc(F)c(=O)[nH]1</smiles>

Fig. 9. Chemical structure of 5-fluorouracil (5FU).

5-fluorouracil is involved in DNA synthesis and inhibits the formation of RNA. Both actions are combined to promote a metabolic imbalance that ultimately kills the cell. The inhibitory activity of the drug, by analogy with uracil nucleic acid affect the growth of neoplastic cells, preferably taking advantage of the molecule of uracil for nucleic acid biosynthesis. The effects of DNA and RNA deprivation are more affected cells grow and multiply without control over the normal. Its effectiveness is that it binds irreversibly to the enzyme thymidylate synthase, essential for the synthesis of thymine nucleotides. Thymine is one of four nitrogenous bases that make up the DNA, and lack means that DNA cannot replicate, which inhibits cell division and therefore tumor growth. 5FU structure shown in figure 9.

\section{Study of the release kinetics measured by HPLC}

To keep track of the release rate of 5FU from the NIPA copolymer nanogels NPAM2AAECM-HPLC was previously required a calibration with standards of 5-FU. 5FU standards were prepared at concentrations of $0,10,20,30,40,50,60,70,80,90$ and 100 ppm, and injected into a liquid chromatograph, using the method described in the experimental section. After obtaining the chromatograms of standards, chromatographic peaks were integrated to obtain the area under the curve, the data obtained for this calibration is shown in table 2.

\begin{tabular}{cccc}
\hline STD & Concentration (ppm) & $\begin{array}{c}\text { Peak area } \\
\text { (A.U.) }\end{array}$ & $\begin{array}{c}\text { Retention } \\
\text { time } \mathbf{T}_{\mathbf{R}} \\
\text { (minutes) }\end{array}$ \\
\hline 1 & 100 & 37366 & 6,58 \\
2 & 90 & 33256 & 6,58 \\
3 & 80 & 30749 & 6,56 \\
4 & 70 & 26572 & 6,55 \\
5 & 60 & 22294 & 6,53 \\
6 & 50 & 17353 & 6,51 \\
7 & 40 & 14176 & 6,51 \\
8 & 30 & 11406 & 6,51 \\
9 & 20 & 7615 & 6,51 \\
10 & 10 & 3751 & 6,51 \\
\hline
\end{tabular}

Table 2. Data obtained for calibration standards of 5-FU. 
Before performing the action for the release of 5FU, the nanogels of NIPA-NPAM-2AAECM were loaded with the drug. Recall that the swelling of our nanogels depends on the $\mathrm{pH}$ of the medium in which it is, so a simple yet effective to carry the burden of these the nanogels is to introduce a known amount of nanogel in a concentrated solution of 5FU (known concentration) to a $\mathrm{pH}$ below 4.5 which guarantees that the nanogel will be swollen in the middle. The set is kept under constant magnetic stirring for 2 hours. After the loading time, changing the $\mathrm{pH}$ of the medium to a value greater than 6 , which ensures that the nanogel will be collapsed. Thus, when the nanogel collapses, $5 \mathrm{FU}$ is retained in the polymer network and water solution ejected from the macromolecular matrix.

To quantify the total burden of nanogels was necessary to take a sample of the remaining load, as the difference in concentration, both initial (before loading) and final (after loading), will indicate the amount 5FU retained in the nanogel.

In the first instance, two experiments were conducted 5FU release two different $\mathrm{pH}$ values.

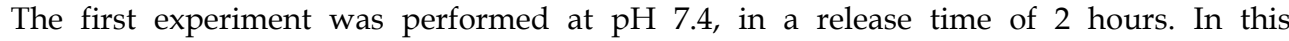
experiment, there should be no release from the nanogel, since, as mentioned above, the nanogel above a value of 5 on the $\mathrm{pH}$ scale is collapsed. However, in this experiment we can see that there is little sign of 5FU in the chromatogram obtained by HPLC, which indicates that in the release medium are molecules of 5FU. This can be attributed to the release of 5-FU molecules absorbed on the surface of nanogel, since the concentration at which $5 \mathrm{FU}$ is in the release medium is very small. This behavior can be seen in figure 10 .

Furthermore, this experiment was to perform the release at $\mathrm{pH} 4$ during a time of 2 hours, which in our case ensures that the polymer network is in a swollen state, allowing the contents within the nanogel 5FU out release to the environment by diffusion effects. As expected, the chromatogram of this test presents a significant peak of $5 \mathrm{FU}$ in a retention time of 6.7 minutes, characteristic of this compound. The chromatogram of this test is shown in figure 11. The total area of this peak has a value of 16,890 A.U.

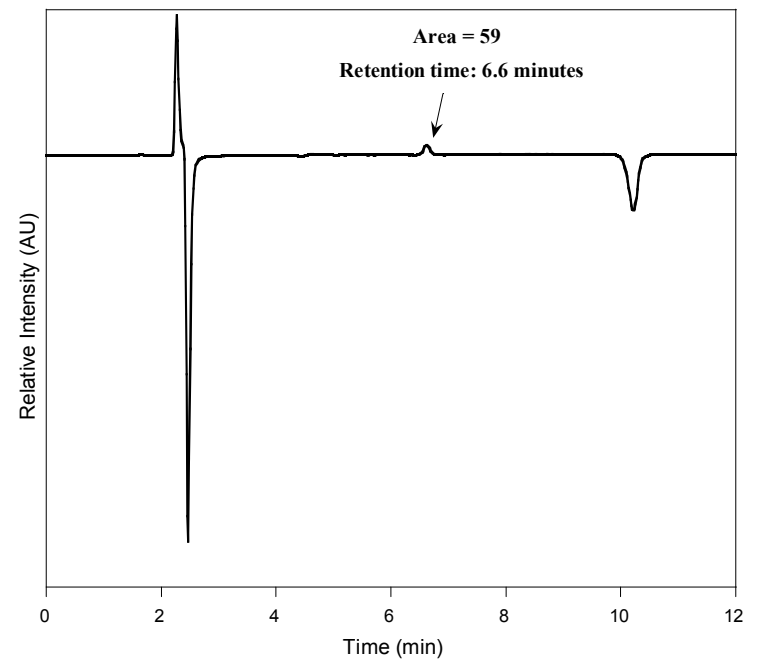

Fig. 10. Chromatogram of a sample of nanogel after 2 hours of release at $\mathrm{pH} 7.4$. 


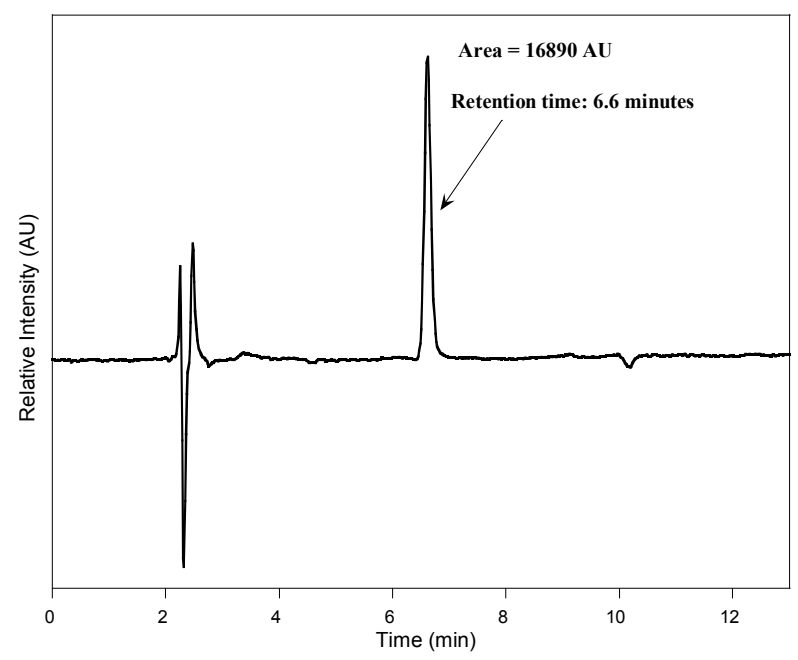

Fig. 11. Chromatogram of a sample of nanogel after 2 hours of release at $\mathrm{pH} 4$.

\section{Conclusions}

We have synthesized a new $\mathrm{pH}$ - and T-responsive smart copolymeric nanohydrogel by inverse microemulsion polymerization. The size particle was determinate by QELS showing an average value of $33 \mathrm{~nm}$. The success of the synthesis was confirmed by FTIR, ${ }^{1} \mathrm{H}$ NMR and DSC. A versatile and successful synthetic strategy to obtain potential nanodevices for targeted drug delivery has been designed. NPA-based copolymeric microgels have been employed as reactive substrate for specific derivatization that led to a smart biomedical function. These precursor microgels were easily chemically modified by aminolysis reaction with amino derivatives to achieve two purposes: firstly, to introduce linkage sites for bonding with the tumor guiding molecule folic acid, which is coupled to the folate receptors in the surface of tumor cells and once internalized by receptor-mediated endocytosis, swell as result of the difference of $\mathrm{pH}$ and secondly, to get a specific swelling behavior that determines the capability of the microgels for intelligent therapy. The functionalization with 4-MP leads to an interesting $\mathrm{pH}$-driven swelling transition. This $\mathrm{pH}$-selective swelling potentially leads to an exclusive release of antitumoral drug into the cancer cells. The networks drastically swell when external $\mathrm{pH}$ varies from neutral to $\mathrm{pH}$ values around 5 . There are some facts that influence this swelling behavior, such as copolymer composition.

\section{Acknowledgements}

The financial support from the Ministerio de Ciencia y Tecnología of Spain is gratefully acknowledged.

\section{References}

Agüero L., Guerrero-Ramírez L.G. \& Katime I., 2010, “New Family of Functionalized Monomers Based on Amines: A Novel Synthesis that Exploits the Nucleophilic Substitution Reaction" , Materials Sciences and Applications, 1, 103-108, ISSN: 2153-1198. 
Alléman E., Doelker E. \& Gurny R., 1993, “Drug-loaded nanoparticles-preparation methods and drug targeting issues", Eur. J. Pharm. Biopharm., 39(1), 13-20, ISSN: 0939-6411.

Anderson R. G., Kamen B. A., Rothgber K.G. \& Lacey S.W., 1992, "Potocytosis: sequestration and transport of small molecules by caveolae", Science, 255, 410, ISSN: 0036-8075

Antonietti M. \& Bremser W., 1990, "Microgels: model polymers for the crosslinked state", Macromolecules, 23, 3796-3805, ISSN: 0024-9297.

Bleiberg H., Hulstaert F., Buyse M. \& De Keyser P., 1998, "Tropisetron in the prevention of acute and delayed nausea and vomiting over six courses of emetogenic chemotherapy, Anti-cancer drugs, 9(9), 773 ISSN: 0959-4973.

Boggs L.J., Rives M. \& Bike S.G., 1996, “Characterization and rheological investigation of polymer microgels used in automotive coatings", J. Coat Technol, 68(855), 63, 63-74, ISSN: 0361-8773

Bokias G., Hourdet D., Ilipoulos I., Staikos G. \& Audebert R., 1997, “Hydrophobic Interactions of Poly( $N$-isopropylacrylamide) with Hydrophobically Modified Poly(sodium acrylate) in Aqueous Solution" Macromolecules, 30, 8293, ISSN: 00249297.

Bronstein L.M., 2004, Encyclopedia of Nanoscience and Nanotechnology. Nalwa H.S. (editor), vol 7, 193-214, ISSN: 1550-7033. Indiana University, Bloomington (USA)

Bruck S. D. \& Mueller E. P., 1988, “Radiation Sterilization of polymeric implant materials”, J. Biomed. Mater. Res., 22 (A2), 133-144, ISSN: 1549-3296.

Candau F. \& Buchert P., 1990, "Rheological Studies on inverse microlatices", Colloids Surf., 48, 107-122, ISSN: 0927-7757.

Candau F., Leong Y.S. \& Fitch R.M., 1985, "Kinetic Study of the Polymerization of Acrylamide in inverse microemulsion", J. Polym. Sci. Part. A: Polym. Chem., 23, 193214, ISSN: 1099-0518.

Candau F., Zekhinini Z. \& Durand JP., 1986, “Copolymerization of water-soluble monomers in Non-ionic Bicontinous Microemulsion", J. Colloid Interf. Sci., 114(2), 398-408, ISSN: $1095-7103$

Candau F. \& Zekhinini Z., 1987, “Copolymerization of acrylamide and sodium acrylate in microemulsions", Prog. Colloid and Sci., 73, 33-36, ISSN: 0340-255X

Castro López V., Hadgraft J. \& Snowden M.J., (2005), “The use of colloidal microgels as a (trans)dermal drug delivery system", Int. J. Pharm., 292, 137-147. ISSN: 0378-5173.

Choi H.S., Kim J.M., Lee K.J. \& Bae Y.C., 1988, "Volume phase transition behavior of $N$ isopropyl acrylamide- $N$-cyanomethyl acrylamide copolymer gel particles: The effect of crosslinking density", J Appl. Polym. Sci., 72(8), 1091-1099. ISSN: 1097-4628.

Coney L.R. Tomaselti A., Carayannopoulos, L. Frasca, V., Kamen B.A., Colnaghi M. I. \& Zurawski V.R., 1991, “Cloning of a tumor-associated antigen-MOV18 and MOV19 Antibodies recognize a folate-binding protein", J. Cancer Res., 51, 6125-6132. ISSN: 1538-7445

Corkhill P.H., Jolly A.M., Ng C.O. \& Tighe B.J., 1987, “Synthetic hydrogels. 1. Hydroxyalkyl acrylate and methacrylate copolymers-water binding-studies", Polymer, 28, 17581766. ISSN: 0032-3861

Orrah D.J., Semlyen J.A. \& Ross-Murphy S.B., 1988, "Studies of cyclic and linear Poly(Dimethylsiloxanes). 27. Bulk Viscosities above the Critical Molar Mass for Entanglement", Polymer, 29, 1452-1454, ISSN: 0032-3861. 
Downey J.S., Frank R.S., Li WH. \& Stover H.D.H, 1999, “Growth mechanism of poly(divinylbenzene) microspheres in precipitation polymerization", Macromolecules, 32, 2838-2844, ISSN: 1520-5835.

Dubé D., Francis M., Leroux J.C., Francoise M. \& Winnik D., 2002, “Preparation and tumor cell uptake of poly(N-isopropylacrylamide) folate conjugates", Biocojugate Chem., 13, 685-692. ISSN: 1520-4812.

Escalante I. I., Rodríguez-Guadarrama L.A.; Mendizábal E., Puig J., López R.G. \& Katime I., 1996, "Synthesis of Poly(butyl methacrylate) in Three-Component Cationic Microemulsions", J. Appl. Polym. Sci., 62(9), 1313-1323. ISSN: 1097-4628

Franson N.M. \& Pepas N.A., 1983, "Influence of copolymer composition on Non-Fickian water transport through glassy copolymers", J. Appl. Polym. Sci., 28, 1303-1310. ISSN: 1097-4628.

Funke W., Okay O. \& Joos-Müller B., 1998, “Microgels - Intramolecularly crosslinked macromolecules with a globular structure", Adv. Polymer Sci., 136, 139-234 ISSN: 1436-5030.

Garin-Chesa P., Camell I., Saigo P., Lewis J., Old L. \& Retting W., 1993, “In vitro detection of occult bone marrow metastases in patients with colorectal cancer hepatic metastases", Am. J. Pathol., 42, 557, ISSN: 0887-8005.

Guerrero L.G., Hervías X., Nuño-Donlucas S., Cesteros L.C., Sanz L. \& Katime I., 2008, "Synthesis of nano-structured copolymeric hydrogels based on N-Isopropyl acrylamide (NIPA) by Microemulsion Polymerization", Nanospain Congress, Braga Portugal.

Guerrero L.G., Nuño-Donlucas S., Cesteros L.C., Sanz L. \& Katime I., 2008, “Study of drug release on smart nano-sized hydrogels based on $\mathrm{N}$-isopropyl acrylamide by High Performance Liquid Chromatography", Nanospain Congress, Braga Portugal

Guerrero-Ramírez L.G., Nuño-Donlucas S.M., Cesteros L.C. \& Katime I., 2008, Material Chemistry \& Physics, 112(3), 1088-1092, ISSN: 0254-0584.

Guerrero-Ramírez L.G., Nuño-Donlucas S.M., Cesteros L.C. \& Katime I., 2008, J. Physics Conference Series, J. Phys.: Conf. Ser., 127, 012010, ISSN: 1742-6596.

Hoar T.P. \& Schulman J.H., 1943, “Transparent water in oil dispersions: the oleopathic hydromicelle", Nature, 102, 2252, ISSN: 1476-4687.

Katime I., Katime O. \& Katime D., 2004 "Los materiales inteligentes de este milenio: Los hidrogeles macromoleculares. Sintesis, propiedades y aplicaciones". Servicio Editorial de la Universidad del País Vasco. Bilbao. ISBN: 84-8373-637-3

Katime I., Arellano J., Mendizábal E. \& Puig J., 2001, "Synthesis and characterization of poly(n-hexyl methacrylate) in three-component microemulsion", Eur. Polym. J., 37(11), 2273-2279, ISSN: 0014-3057.

Katime I. \& Mendizábal E., 1997, "Influence of physico-chemical parameters on the kinetics of microemulsion polymerization", Recent. Res. Devel. Polymer Sci., 1, 271-289, ISBN: 81-7736-157-0

Katime I., Quintana J.R., Valderruten N. \& Cesteros L.C., 2006, Macromol. Chem. Phys., 207, 2121-2127, ISSN: 1521-3935.

Katime I., Química Física Macromolecular, 1994, Servicio Editorial UPV/EHU, Bilbao. ISBN: 84-7585-583

Kazakov S., Kaholek M., Teraoka I. \& Levon K. 2002, “UV-induced gelation on nanometer scale using liposome reactor", Macromolecules, 35,1911-1920, ISSN: 1520-5835. 
Krane A.R. \& Peppas N. A., 1991, “Gel Syneresis as a Method to Release Drugs at Prescribed intervals", Polymer News, 16, 230-240. ISSN: 0032-3918.

Küdela V., Encyclop. Polym. \& Technol., 1987, Kroschwitz J.I. (editor), 7, 783, Wiley, New York. ISBN: 9780471440260.

Kurauchi K., Shiga T. \& Yokada H. A., 1991, "Polymer Gels: Fundamentals and Biomedical applications", De Rossi D. , Kajiwara K., Osada Y. \& Yamauchi A. (eds.) Plenum Press, New York, 237

Kwon I.C., Bae Y.H. \& Kim S.W., 1991, "Electrically erodible polymer gel for controlled release of drugs", Nature, 354(6351): 291-293. ISSN: 1476-4687.

Brannon-Peppas L., 1997, "Polymers in Controlled Drug Delivery", Medical Plastics and Biomaterials, 4, 34-44. ISSN: 1083-5466.

Lee R.J, Wang S. \& Low P.S., 1996, "Measurement of endosome $\mathrm{pH}$ following folate receptor-mediated endocytosis", Biochim. Bioph. Acta, 1312, 237-242. ISSN: 00052736.

Lee R.J. \& Low P. S., 1994, "Delivery of liposomes into cultured KB cells via folate receptormediated endocytosis", J. Biol. Chem., 269(5), 3198-3204. ISSN: 0021-9258.

Mamada A., Tanaka T., Kungwatchakun D., Irie M., 1990, "Photoinduced Phase-Transition of Gels", Macromolecules, 23(5) 1517-1519. ISSN: 1520-5835.

Mathur A. M. \& Scranton A. B., 1996, “Characterization of hydrogels using nuclear magnetic resonance spectroscopy", Biomaterials, 17, 547-557, ISSN: 0142-9612.

Mendizábal E., Flores J., Puig J., Katime I., Lopez-Serrano F. \& Alvarez J., 2000, "On the modeling of microemulsion polymerization. Experimental validation", Macromolecular Chemistry and Physics, 201(12), 1259-1265, ISSN: 1022-1352.

Murray M.J. \& Snowden M.J., 1995, “The preparation, characterization and applications of colloidal microgels", Adv. Colloid Interf. Sci., 54, 73-91, ISSN: 0001-8686.

Naka Y. \& Yamamoto Y., 1998, "Preparation of poly(aryleneethynylene)-type copolymers containing flexible linking methylene units. Optical properties of the copolymers suggesting occurrence of energy transfer between $\Pi$-conjugated local units", $J$. Polym. Sci. Part A: Polym. Chem., 36(13), 2209-2214, ISSN: 1099-0518.

Osada Y., Umeawa K. \& Yamauchi A., Macromol Chem., 1989, 189, 3859. ISSN: 1521-3935.

Pelton R., 2000, "Temperature-sensitive aqueous microgels", Adv. Colloid Interf. Sci., 85(1), 133, ISSN: 0001-8686.

Pérez L., Sáez V., Heráez E. \& Katime I., 2008, “Synthesis and characterization of pHsensitive microgels by derivatization of NPA-based reactive copolymers", Materials Chemistry and Physics, 112 (2), 516-524, ISSN: 0254-0584

Pérez L., Sáez V., Heráez E. \& Katime I., 2009, “Novel pH and Temperature Responsive Methacrylamide Microgels", Macromolecular Chemistry and Physics, 210, 1120-1126, ISSN: 1022-1352.

Pérez L., Sáez V., Heráez E., Rodríguez E. \& Katime I., 2005, “Synthesis and characterization of reactive copolymeric microgels", Polym. Int. 54, 963-971, ISSN: 1097-0126.

Rivolta, C.M., Moya, Christian M. \& Esperante S.A., Medicina (B. Aires). 2005, “The thyroid as a model for molecular mechanisms in genetic diseases", 65(3), 257-267, ISSN: 1669-9106.

Ross J.F., Chaudhuri, R.K. \& Ratnam M., Cancer, 1994, “Differential regulation of folate receptor isoforms in normal and malignant-tissues in vivo and in established celllines-physiological and clinical implications", 73, 2432-2443, ISSN: 1097-0142. 
Saunders B.R. \& Vincent B., 1999, “Microgel particles as model colloids: theory, properties and applications", Adv. Colloid Interf. Sci., 80(1), 1-25, ISSN: 0001-8686.

Stubbs M. , MeSheedy P.M.J., Griffiths J.R. \& Bashford C.L., 2000, “Causes and consequences of tumour acidity and implications for treatment", Mol. Med. Today, 6(1), 15-19, ISSN: $1357-4310$

Sudimack J. \& Lee R.J., 2000, "Targeted drug delivery via the folate receptor", Adv. Drug Deliv. Rev., 41(2), 147-162., ISSN: 0169-409X.

Thompson S. Gandhi M.V., 1988, "Smart materials know when to change properties". Metal Progress, 134(3), 22-25, ISSN: 1335-8987.

Tanaka H., Touhara H., Nakanishi K. \& Watanabe N., 1984, “Computer experiment on aqueous solution. IV. Molecular dynamics calculation on the hydration of urea in an infinitely dilute aqueous solution with a new urea-water pair potential ", $J$. Chem. Phys., 80(10), 5170-5176. ISSN: 0021-9606.

Tannock L. \& Rotin D., 1989, “Acid $\mathrm{pH}$ in Tumors and Its Potential for Therapeutic Exploitation", Cancer Res., 4, 4373-4384, ISSN: 1538-7445.

Thomson R.A.M., 1983 "Chemistry and Technology of water-soluble polymers", Finch A. (Editor). Plenum. New York

Vert M., 1986, Crit. Rev. Ther. Drug Carrier Syst., 2, 291-297, ISSN: 0743-4863.

Weitman D. \& Etlinger J.D., 1992, “A monoclonal antibody that distinguishes latent and active forms of the proteasome (multicatalytic proteinase complex)", J. Biological Chem., 267(10), 6977-6982, ISSN: 0021-9258

Zhang X.Z., Yang Y.Y. \& Chung T.S., 2002, “The influence of cold treatment on properties of temperature-sensitive Poly(N-isopropylacrylamide) hydrogels", J. Colloid Interface Sci., 246(1), 105-108, ISSN: 0021-9797.

Zhu Z., Xue R. \& Yu Y.C., 1989, “Toughening of epoxy-polyamide adhesives with rubbery reactive microgels", Angew. Makromol. Chem. 171, 65-77, ISSN: 0003-3146. 


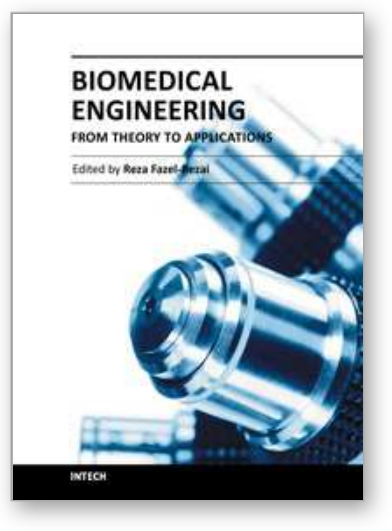

\author{
Biomedical Engineering - From Theory to Applications \\ Edited by Prof. Reza Fazel
}

ISBN 978-953-307-637-9

Hard cover, 486 pages

Publisher InTech

Published online 29, August, 2011

Published in print edition August, 2011

In all different areas in biomedical engineering, the ultimate objectives in research and education are to improve the quality life, reduce the impact of disease on the everyday life of individuals, and provide an appropriate infrastructure to promote and enhance the interaction of biomedical engineering researchers. This book is prepared in two volumes to introduce a recent advances in different areas of biomedical engineering such as biomaterials, cellular engineering, biomedical devices, nanotechnology, and biomechanics. It is hoped that both of the volumes will bring more awareness about the biomedical engineering field and help in completing or establishing new research areas in biomedical engineering.

\title{
How to reference
}

In order to correctly reference this scholarly work, feel free to copy and paste the following:

L.G. Guerrero-Ramirez and Issa Katime (2011). Nano-Engineering of Complex Systems: Smart Nanocarriers for Biomedical Applications, Biomedical Engineering - From Theory to Applications, Prof. Reza Fazel (Ed.), ISBN: 978-953-307-637-9, InTech, Available from: http://www.intechopen.com/books/biomedical-engineeringfrom-theory-to-applications/nano-engineering-of-complex-systems-smart-nanocarriers-for-biomedicalapplications

\section{INTECH}

open science | open minds

\section{InTech Europe}

University Campus STeP Ri

Slavka Krautzeka 83/A

51000 Rijeka, Croatia

Phone: +385 (51) 770447

Fax: +385 (51) 686166

www.intechopen.com

\section{InTech China}

Unit 405, Office Block, Hotel Equatorial Shanghai

No.65, Yan An Road (West), Shanghai, 200040, China 中国上海市延安西路65号上海国际贵都大饭店办公楼 405 单元

Phone: +86-21-62489820

Fax: +86-21-62489821 
(C) 2011 The Author(s). Licensee IntechOpen. This chapter is distributed under the terms of the Creative Commons Attribution-NonCommercialShareAlike-3.0 License, which permits use, distribution and reproduction for non-commercial purposes, provided the original is properly cited and derivative works building on this content are distributed under the same license. 